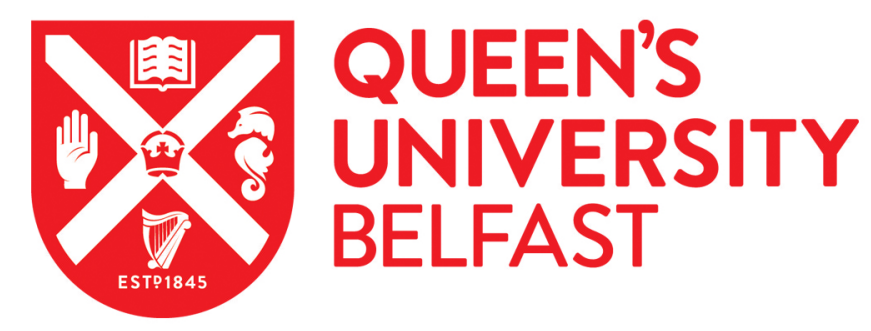

\title{
Regret minimisation and utility maximisation in a freight transport context
}

Boeri, M., \& Masiero, L. (2014). Regret minimisation and utility maximisation in a freight transport context. Transportmetrica A: Transport Science, 10(6), 548-560. https://doi.org/10.1080/23249935.2013.809818

\section{Published in:}

Transportmetrica A: Transport Science

\section{Document Version:}

Peer reviewed version

Queen's University Belfast - Research Portal:

Link to publication record in Queen's University Belfast Research Portal

\section{Publisher rights}

This is an Accepted Manuscript of an article published by Taylor \& Francis available online:

http://wwww.tandfonline.com/DOI:10.1080/23249935.2013.809818

\section{General rights}

Copyright for the publications made accessible via the Queen's University Belfast Research Portal is retained by the author(s) and / or other copyright owners and it is a condition of accessing these publications that users recognise and abide by the legal requirements associated with these rights.

Take down policy

The Research Portal is Queen's institutional repository that provides access to Queen's research output. Every effort has been made to ensure that content in the Research Portal does not infringe any person's rights, or applicable UK laws. If you discover content in the Research Portal that you believe breaches copyright or violates any law, please contact openaccess@qub.ac.uk. 


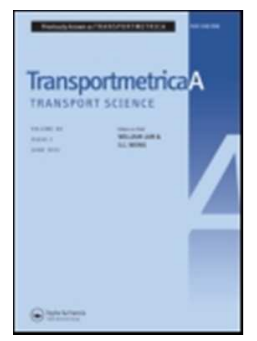

\section{Regret minimization and utility maximization in a freight transport context}

\begin{tabular}{|r|l|}
\hline Journal: & Transportmetrica A: Transport Science \\
\hline Manuscript ID: & TTRA-2012-0020.R3 \\
\hline Manuscript Type: & Full Paper \\
\hline Date Submitted by the Author: & n/a \\
\hline Complete List of Authors: & $\begin{array}{l}\text { Boeri, Marco; Queen's University of Belfast, Gibson Institute for Land, Food } \\
\text { and the Environment School of Biological Sciences } \\
\text { Masiero, Lorenzo; The Hong Kong Polytechnic University, School of Hotel } \\
\text { and Tourism Management }\end{array}$ \\
\hline Keywords: & $\begin{array}{l}\text { Random regret minimization, Random utility maximization, Freight } \\
\text { transport, Stated preference, Shift of reference point }\end{array}$ \\
\hline \multicolumn{2}{|c}{} \\
\hline
\end{tabular}

\section{SCHOLARONE ${ }^{m}$}

Manuscripts 


\title{
Regret minimization and utility maximization in a freight transport
} context

\author{
Abstract: \\ This study is the first to compare random regret minimization (RRM) and random \\ utility maximization (RUM) in freight transport application. This paper aims to \\ compare RRM and RUM in a freight transport scenario involving negative shock \\ in the reference alternative. Based on data from two stated choice experiments \\ conducted among Swiss logistics managers, this study contributes to related \\ literature by exploring for the first time the use of mixed logit models in the most \\ recent version of the RRM approach. We further investigate two paradigm \\ choices by computing elasticities and forecasting choice probability. We find that \\ regret is important in describing the managers' choices. Regret increases in the \\ shock scenario, supporting the idea that a shift in reference point can cause a shift \\ toward regret minimization. Differences in elasticities and forecast probability \\ are identified and discussed appropriately.
}

Keywords: Random regret minimization, Random utility maximization, Freight transport, Stated preference, Shift of reference point

\section{Introduction}

Discrete choice modeling applications are generally based on (linear) random utility maximization (RUM) theory (Thurstone, 1927; Manski, 1977) and the derived logit model (McFadden, 1974, Ben-Akiva \& Lerman, 1985; Train, 2009). However, growing evidence suggests that the choice paradigm based on RUM lacks behavioral realism in some occasions (see Hess et al., 2012).

The random regret minimization (RRM) approach to discrete choice modeling is a relatively new choice paradigm that relaxes the assumption of utility maximization, remaining econometrically as parsimonious and tractable as its utilitarian counterpart, 
the RUM (Chorus, 2010). The RRM-based multinomial logit (MNL) model is built on the notion that people aim to minimize regret rather than maximize utility when choosing; in this situation, regret is defined as what a person experiences when a nonchosen alternative performs better than a chosen one in terms of one or more attributes ${ }^{1}$.

Although only recently introduced in transportation (Chorus, 2010), different applications that focus on comparing the outcomes of the RUM and RRM models are emerging in different fields, including choices among shopping destinations and parking lots (Chorus, 2010), road pricing policies (Chorus et al., 2011), departure times (Chorus \& de Jong, 2011), travel mode (Pathan, 2010), travel choice (Chorus et al., 2008), route choices and traffic equilibria (Chorus, 2012a), automobile fuel choice (Hensher et al., 2011), drivers' choices of crash avoidance (Kaplan and Prato, 2012), online dating profiles (Chorus and Rose, 2011), recreational activities (Thiene et al., 2012 and Boeri et al., 2012), and health economics (Boeri et al., 2013).

The short literature review ${ }^{2}$ performed in this present study indicates that none of the applications are in the context of freight transport and that the comparison between the RRM and RUM models is exclusively based on MNL model specifications

\footnotetext{
${ }^{1}$ The idea that regret minimization is an important choice behavior is well established in many fields, namely, marketing (Simonson, 1992; Zeelenberg and Pieters, 2007), microeconomics (Loomes and Sugden, 1982; Sarver, 2008), psychology (Zeelenberg, 1999; Connolly, 2005), management sciences (Savage, 1954; Bell, 1982), and transportation (Chorus et al., 2006, 2009). The random regret minimization approach to discrete choice models translates this conceptual notion into an operational, easily estimable logit model for the analysis of risky (Chorus, 2012a) and riskless choices (Chorus, 2010).

${ }^{2}$ For a more exhaustive overview of comparisons between RUM and RRM, see Chorus (2012c).
} 
and does not include the comparison of the mixed logit (MXL) models ${ }^{3}$. Given the strategic importance of understanding the preferred transport modes of logistics managers, this study contributes to related literature by presenting the first application of the RRM model to freight transport and by comparing the RUM- and RRM-based MXL models. This comparison allows for random taste heterogeneity among respondents and acknowledges the error component structure nesting similar freight transport options (without cross-nesting). We further provide an interesting comparison between RUM and RRM under different random heterogeneity distribution assumptions by estimating the two versions of MXL models. The first model assumes that the coefficients are normally distributed, whereas the other assumes a constrained triangular distribution where the standard deviation of the coefficients is set to be equal to the mean value ${ }^{4}$.

Our analysis indicates that the underlying assumption of the RRM approach becomes particularly interesting when the reference alternative is specifically manipulated (i.e., shifted) for research purposes, especially in applications that

\footnotetext{
${ }^{3}$ We acknowledge that Hess et al. (2012) allowed for heterogeneity within the RRM model but did not observe such. We further note that Hess et al. (2012) referred to the version of RRM proposed in 2008 (alternative specific regret; Chorus, et al. 2008). This current paper refers to the version of RRM developed in 2010 (attribute specific regret; Chorus, 2010).

${ }^{4}$ The use of constrained triangular distribution ensures that the estimated coefficient is consistent with the micro-economic perspective (for further details, see Hensher and Greene, 2003). As noted by an anonymous reviewer, distributions with estimated bounds can better identify mean and heterogeneity, but they require significantly more computational time.
} 
introduce worsening effects to simulate negative shock. Respondents tend to minimize anticipated regret rather than maximize utility when faced with a decision in a modified scenario as a result of the increased feeling of responsibility associated with the choice that has to be made (Zeelenberg and Pieters, 2007). Furthermore, it is reasonable to expect that the probability of regret being considered instead of utility increases in the case of negative shock given that the respondents are already facing an incurred loss. Therefore, another contribution of this paper to related literature is the exploration of how the comparison between RUM and RRM model varies in two scenarios: a baseline scenario with a defined reference point and a scenario involving negative shock in the reference alternative.

The remainder of the paper is organized as follows: Section 2 presents the methodology, Section 3 describes the dataset, and Section 4 presents the empirical analyses based on the case study. RRM and RUM are compared in terms of parameter estimates, goodness of fit, elasticity, and policy scenario. Section 5 presents the conclusions and avenues for further research.

\section{Methodology}

The specification of the linear parameter utility function in the RUM choice paradigm (Thurstone, 1927; Manski, 1977) is provided by

$$
\mathrm{U}_{\mathrm{ni}}=\beta^{\prime} \mathrm{X}_{\mathrm{ni}}+\varepsilon_{\mathrm{ni}}
$$

where $i$ is the alternative selected by respondent $n, \mathrm{X}$ is a vector with $m$ attributes, $\beta$ is a vector with $m$ parameters to be estimated, and $\varepsilon$ is an independent and identically 
distributed (i.i.d.) error term representing the unobserved part of the utility and is extreme value type I-distributed.

Given the utility function of Equation 1, choice probability is represented by an RU-MNL model as follows (McFadden, 1974):

$$
\operatorname{Pr}_{n^{(i)}}=\frac{e^{V_{i n}}}{\sum_{j=1}^{J} e^{V_{j n}}}
$$

where $V_{\text {in }}=\beta^{\prime} X_{\text {ni }}$.

The regret function in an RRM framework is represented as

$$
\Psi_{\text {ni }}=\mathrm{R}_{\text {ni. }}+\omega_{\text {ni }}
$$

where $\mathrm{R}_{\mathrm{ni}}$ is observed anticipated regret associated with the choice of alternative $i$ among $j$ alternatives and $\omega$ is an extreme value type I-distributed i.i.d. error term representing the unobserved part of regret. The level of observed anticipated regret associated with the choice of alternative $i$ among $j$ alternatives, each of which is described in terms of $m$ attributes, can be written as follows (Chorus, 2010):

$$
R_{i}=\sum_{j \neq i} \sum_{m=1 . ., M} \ln \left(1+e^{\theta_{m}\left(x_{j m}-x_{i m}\right)}\right)
$$

where $\theta$ is a vector with $m$ parameters to be estimated. The observable part of regret associated with a choice is represented by the sum of all the "binary regrets" associated with comparing all attributes $m$ in alternative $i$ with all attributes $m$ in the other alternative $j$ in the choice set. Acknowledging the fact that minimizing random regret is mathematically equivalent to maximizing negative random regret, the probability of 
individual $n$ selecting alternative $i$ over any other alternative $j$ in the choice set is represented by the RR-MNL model as follows (Chorus, 2010) ${ }^{5}$ :

$$
\operatorname{Pr}_{n^{(i)}}=\frac{e^{\left(-R_{i}\right)}}{\sum_{j=1}^{J} e^{\left(-R_{j}\right)}}
$$

Equations 2 and 5are the logit formulas for the RU-MNL and RR-MNL models, respectively. The preferences in these two specifications are assumed to be homogeneous in all observations and individuals. Although this assumption may be true in most cases, a number of empirical studies have shown that heterogeneity often exists in the preferences that individuals have for different attributes. The limitations of the MNL model in accommodating preference heterogeneity have allowed the development of a suite of models that can be classified as MXL models. The central feature of MXL models is the ability of these models to accommodate random taste variation, unrestricted substitution patterns, and correlation in unobserved factors over time (Train, 2009). MXL models allow researchers to incorporate in their analysis a normal error component structure, including alternative specific variances, nesting and crossnesting, and agent effects on panel data (Walker et al., 2007). MXL models significantly improve the model fit (Hensher and Greene, 2003; Rigby et al., 2009) and provide greater insights into choice selection (McFadden and Train, 2000) and welfare estimation (Sillano and Ortúzar, 2005; Scarpa et al., 2008; Daly et al., 2009; Hynes et al., 2008).

\footnotetext{
${ }^{5}$ Negative random error $\omega$ is distributed in extreme value type I.
} 
This paper aims to apply an MXL formulation to the RRM model in freight transport to consider the panel nature of the data, accommodate both unobserved heterogeneity in preferences and an error component nesting structure, and compare RRM with RUM under this specification. As highlighted by Chorus (2012b), the extension towards RRM-based mixed logit (RR-MXL) models is as straightforward as in the case of RUM-based MXL(RU-MXL) models. MXL models can provide a flexible, theoretical, and computationally practical econometric method for any discrete choice (McFadden and Train, 2000).

If the values of the estimated parameter vector in an MXL model are known with certainty for each respondent, then the probability of respondent $n$ 's sequence of choices would be provided by

$$
\begin{aligned}
& \operatorname{Pr}\left(y_{n}^{t} \mid \beta_{n}, X_{n}\right)=\prod_{t=1}^{T} \frac{e^{\left(V_{\text {int }}\right)}}{\sum_{j=1}^{J} e^{\left(V_{j n t}\right)},} \\
& \operatorname{Pr}\left(y_{n}^{t} \mid \theta_{n}, X_{n}\right)=\prod_{t=1}^{T} \frac{e^{\left(-R_{\text {int }}\right)}}{\sum_{j=1}^{J} e^{\left(-R_{j n t}\right)}},
\end{aligned}
$$

where $y_{n}^{t}$ is the sequence of choices over T choice occasions for respondent $n$. Given that determining the value of the parameters with certainty for each respondent is impossible, random variation is allowed to facilitate the estimation of heterogeneity for all respondents. Unconditional choice probability is obtained in this condition by integrating the product of logit probabilities over the distribution of $\beta_{\mathrm{n}}$ into the RUMXL models 


$$
\operatorname{Pr}\left(y_{n}^{t} \mid \beta_{n}, X_{n}\right)=\int \prod_{t=1}^{T} \frac{e^{V_{i n t}}}{\sum_{j=1}^{J} e^{V_{j n t}}} f(\beta) d \beta
$$

and by integrating the product of logit probabilities over the distribution of $\theta_{n}$ into the RR-MXL models

$$
\operatorname{Pr}\left(y_{n}^{t} \mid \theta_{n}, X_{n}\right)=\int \prod_{t=1}^{T} \frac{e^{\left(-R_{i n t}\right)}}{\sum_{j=1}^{J} e^{\left(-R_{j n t}\right)}} f(\theta) d \theta
$$

The analyses were performed with Biogeme 2.2 (see Bierlaire, 2003, 2009), a new and flexible version of Biogeme based on Python programming language. The models were estimated by the CFSQP algorithm (Lawrence et al., 1997); the repeated choice (panel) nature of the data was considered. Given that the choice probabilities in Equations 8 and 9 have no closed form and cannot be calculated exactly, we estimated the RR-MXL and RU-MXL models through maximum simulated likelihood (MSL) with 1000 quasi-random draws via Latin-hypercube sampling (see Hess et al., 2006, for further details). Two versions of the RU-MXL and RR-MXL specifications were then estimated, allowing the values of the taste parameters to vary among the individual respondents following normal and constrained triangular distributions, respectively. Both versions considered nesting error components to control correlation among similar freight transport options ${ }^{6}$.

\footnotetext{
${ }^{6}$ Considering the error component nesting specifications result in correctly identified models as shown in Walker et al. (2007), pages 1107 to 1109 and page 1112 for panel data. The models in the present study were further tested through estimation based on different random starting values (following the procedure for Python biogeme proposed by Boeri in 2011).
} 


\section{Application to freight transport}

The data utilized for estimation were obtained from two stated preference (SP) experiments conducted in 2008 among the logistics managers of medium to large manufacturing industries located in Ticino (Switzerland). The experiments aimed to identify the indirect costs associated with the temporary closure of the Gotthard road corridor, one of the most important Alpine road corridors connecting the north and south of Europe ${ }^{7}$.

The two experiments involved selecting among the labeled alternatives that describe freight transport services in terms of transportation mode, transport time, transport cost, and punctuality of the transport. The attribute levels for transport time and cost were derived according to positive and negative percentage deviations around the values stated by the logistics managers for a typical freight transport service going to or coming from the northern side of the Alps. The attribute levels for punctuality were introduced in terms of absolute values.

Table 1 presents the attributes and their levels in the two SP experiments and the descriptive statistics for the typical freight transport service described by the logistics managers. The main difference between the two experiments is the reference values utilized to set the scenarios. The first experiment (base scenario) considered the actual values stated by the logistics managers for the typical transport service. On the contrary, the second experiment (shock scenario) considered the transitional values reflecting the

\footnotetext{
${ }^{7}$ For more details on the study, see Masiero and Maggi (2012).
} 
temporary and worsening manipulation (as a result of negative shock) applied to the actual values ${ }^{8}$. As can be seen in the bottom part of Table 1, negative shock involves freight transports that, on the average, require $500 \mathrm{CHF}$ and are two hours longer in duration than the typical transport. Transport punctuality is also affected, decreasing by two percent points with minimum threshold set at 96 percent $^{9}$.

With regard to transportation mode, the road alternative represents the status quo (i.e., the reference alternative) being the preferred transportation mode for typical freight transport described by the logistics managers. Aside from the status quo, the first SP experiment considered two hypothetical alternatives, namely, piggyback (PB, i.e., truck carried on train) and combined transport (TC, which is a combination of road and rail transportation modes). The status quo in the second experiment (shock scenario) was replaced by transitional status quo, which is the actual second-best road alternative (SR, San Bernardino road corridor). As for the hypothetical alternatives, PB and TC were considered as well as a third hypothetical alternative representing a regulated road (which simulates a congestion-free San Bernardino road corridor) and assuming a priority policy that allows the original punctuality to be maintained.

[Insert Table 1 here.]

The two SP experiments involved 15 choice tasks each and were conducted sequentially through face-to-face computer-assisted personal interview (CAPI). A total

\footnotetext{
${ }^{8}$ See Masiero and Hensher (2011) for application of similar data on shift of reference point in a reference-dependent specification.

${ }^{9}$ The criteria for setting transitional transport were derived from an in-depth phone survey of six of the most important shippers in the region. The criteria reflect the consequences of detour via the second best road alternative, namely, the San Bernardino road corridor.
} 
of 60 medium to large firms were contacted and asked to participate in the survey, resulting in a final sample of 27 firms $(18 \text { medium and } 9 \text { large in size })^{10}$. The sample firms successfully completed the two proposed experiments, resulting in 405 choice observations for each scenario.

\section{Empirical results}

This section reports the results for the MNL and MXL models under RRM and RUM paradigms in the two experiments (before and after the negative shock on the reference point). Table 2 presents the estimates from RU-MNL and RR-MNL, and Tables 3 and 4 present the results from RU-MXL and RR-MXL for the two considered versions of random heterogeneity, namely, normal and constrained triangular distribution.

[Insert Table 2, Table 3, and Table 4 here.]

The estimated coefficients present in all the models introduced in Tables 2, 3, and 4 (i.e., mean coefficients $\beta$ s and alternative specific constants ASCs) are all highly statistically significant in the first experiment. However, the regulated road and secondbest road are not statistically different in the second experiment (the parameter ASC_SR, which is a dummy variable for the second-best road with the regulated road as baseline, is not statistically significant). Considering that the RR-MNL model's underlying behavioral premises are fundamentally different from those in the RU-MNL model, the fact that both models highlight the same differences in the first and second experiments may be considered a sign of robustness for further policy appraisals (a

\footnotetext{
${ }^{10}$ The statistic population comprised 101 medium and 19 large firms operating in the manufacturing sector in Ticino (Swiss Federal Office, Neuchatel).
} 
similar discussion on robustness can be found in the study conducted by Thiene et al. 2012).

The coefficients of time, punctuality, and cost exhibit all the expected signs in all the model estimations. The fact that managers, on the average, dislike transportation modes that imply long travel time or high cost and prefer options with a high probability of punctuality is consistent with the expectations.

Remembering that the interpretation of estimates is not directly comparable with the RUM model is important when analyzing estimates from the RRM approach. A positive and significant coefficient $\beta$, such as the one for punctuality, suggests that regret increases as punctuality increases in a non-chosen alternative (compared with the level of punctuality for the chosen alternative). A negative coefficient for time (and cost) suggests that regret decreases as the difference in time (or cost) between the chosen and non-chosen transportation mode increases because the non-chosen mode requires more time for delivery (or is more expensive).

With regard to the estimates obtained from the MXL models wherein normal distributions are assumed to describe taste heterogeneity (Table 3), we find that the standard deviations of the normal distributions associated with the three $\beta$ coefficients, namely, cost, punctuality, and time, are highly significant in both approaches. This result shows that the presence of heterogeneity in preferences is strong in the sample in both RUM and RRM choice paradigms. Similar results are obtained from the estimates of the MXL models assuming constrained triangular distributions as random parameters (Table 4). The preference heterogeneity in the RUM and RRM choice paradigms is 
bound to either the positive or negative domain to reflect a micro-economic rationale (i.e., negative for time and cost coefficients and positive for punctuality coefficient). Considering the error components, the presence of a nesting structure between similar alternatives is observed for both RU-MXL and RR-MXL models, independent of the distributional assumption considered for random heterogeneity. Both models suggest a significant correlation between alternatives PB and TC in the first experiment. A different pattern is observed in the second experiment between the RU-MXL and RRMXL models assuming constrained triangular distributions (Table 4). The former suggests a significant correlation between PB and TC but not between the preferred road and second-best road alternative. The latter suggests a significant correlation both between PB and TC and between the preferred road and second-best road alternative.

Analysis of the performance of the proposed model specifications indicate that the RRM regret version outperforms its RUM counterpart in all the estimated MNL and MXL models (with the exception of the first experiment presented in Table 4) as indicated by the higher log-likelihood (LL) function and the higher rho-squared $\left(\mathrm{rho}^{2}\right)$ value. Interestingly, this difference is enhanced in the shock scenario as proven by the test for non-nested models ${ }^{11}$ computed for each pair of models presented in Tables 2, 3, and 4. In particular, the LL functions in the first experiment are different (RRM is better than RUM) at 90 percent for the MNL specifications and 95 percent for the MXL specifications, assuming normal distribution of random parameters (a statistically insignificant difference is recorded between the RRM and RUM specifications presented in Table 4). By applying the same test in the second experiment, the

\footnotetext{
${ }^{11}$ We adopted the test for non-nested models explained by Ben-Akiva and Swait (1986).
} 
difference (still in favor of RRM) increases in significance, being significant at 99 percent for MNL and the two MXL specifications.

A more direct comparison between the RUM and RRM model specifications can be established by using parameter estimates to derive direct choice elasticities ${ }^{12}$. The direct choice elasticities derived from the RUM and RRM models provide the percentage change in the choice probability of selecting the transportation mode characterized by a set of attributes caused by a one percentage change in the level of one of the attributes. Unlike in the RUM model, the direct elasticities associated with a change in an alternative's attribute in the RRM model depend on the relative performance of all the alternatives in the choice tasks rather than on the performance (choice probability) of the specific alternative only (Chorus, 2010).

[Insert Table 5 and Table 6 here.]

Direct elasticity values were computed for each characteristic of each transportation mode (time, punctuality, and cost). The computed elasticities from the RU-MNL and RR-MNL model estimates are reported in Tables 5 and 6 for the base and shock scenarios, respectively ${ }^{13}$. Some of the elasticities obtained from RU-MNL are

\footnotetext{
${ }^{12}$ See Hensher et al. (2011) for the formal derivation of elasticities in an estimated RRM model. A routine is available in NLOGIT to compute the RRM-based elasticities. We acknowledge the limitations of computing elasticity values in a stated preference experiment, which are computed in this paper to provide appropriate empirical evidence on the differences in the two choice paradigm assumptions (for further examples, see Hensher er al., 2011 and Thiene et al., 2012).

${ }^{13}$ The elasticities based on MXL estimates can be linked to assumptions on distribution and are difficult to obtain and interpret. As such, the following comparison is based exclusively on estimates obtained from the RU-MNL and RR-MNL specifications.
} 
similar to those obtained from RR-MNL, especially in the first experiment (Table 5). The differences become remarkable in the second experiment (Table 6) where ten of the 12 elasticities estimated from RR-MNL are five percent higher (in absolute value) than the values estimated from RU-MNL. Regarding the reference alternative (road), it is interesting to note that the differences in the elasticity values for cost and time are marginal (less than one percent). A similar pattern is also observed in the second experiment, where the differences between the elasticities derived from RR-MNL and RU-MNL for cost, time, and punctuality for the second-best road are considerably lower than those obtained for the hypothetical alternatives. Four of the nine attributes in the first experiment are more elastic in an RRM context than in an RUM context. Nine of the twelve attributes in the second experiment are more elastic in an RRM context than in an RUM context. RU-MNL in the second experiment generates higher elasticities only for punctuality when the change is in the PB alternative and for cost and time when the change is in TC.

All the attributes are relatively elastic in the two experiments. For example, a one percent increase in punctuality associated with the road alternative results in a 16.22 percent increase in the probability of selecting the road alternative when everything else is held constant. Similarly, a one percent increase in the price of the road alternative reduces the probability of selecting the road by 3.78 percent. Furthermore, in the shock scenario (second experiment), the magnitude of the elasticities increases for all the three investigated attributes compared with the first experiment. This result is a behavioral reaction caused by the negative shock presented 
in the second experiment. Negative shock led to accentuated aversion towards an increase in price and time and a decrease in punctuality.

[Insert Table 7 and Table 8 here.]

A policy scenario was established to better investigate the relevance of the two model outputs in terms of managerial implications in the context of probability forecasting for transportation mode. The policy scenario assumes a 15 percent increase in time for the preferred road and second-best road alternative for the first and second experiments, respectively. In particular, the policy scenario assumes that the increase in travel time is a result of increasing congestion in the status quo alternatives for both experiments. The results from RR-MNL and RU-MNL are reported in Table 7 for the baseline experiment and in Table 8 for the shock experiment.

An increase in transport time suggests, as expected, a decrease in the probability of selecting the preferred road (second-best road in the second experiment). The RUMNL and RR-MNL models result in different probability forecasting. In both experiments, the impact of longer time on the status quo road alternatives as predicted by the RR-MNL model is lower than that predicted by the RU-MNL model. Interestingly, in the assumed policy scenario, the decrease in market share of the status quo alternative predicted by the RR-MNL model is nearly the same in the two experiments: 4.6 percent and 4.5 percent for the first and second experiments, respectively. Conversely, in the RU-MNL model, we observe a 6.5 percent decrease in the market share of the status quo alternative for the first experiment and a 5.3 percent decrease for the second experiment. 


\section{Conclusions and discussion}

This study is the first to compare RRM and RUM in freight transport. The study provides a methodological contribution to related literature by comparing the two approaches to estimate MXL models (RU-MXL and RR-MXL), which allow random heterogeneity in taste and correlation among alternatives. This study is based on two stated choice experiments that investigate if a negative shift in reference point has an impact on logistics managers' approach to choice (i.e., switching from maximizing utility to minimizing regret).

The comparison of RRM and RUM revealed that RR-MNL and one of the two estimated RR-MXL models exhibited a slightly better model fit than their RUM counterparts. The difference in model fit was amplified in the shock scenario, supporting the assumption that regret becomes an important choice paradigm when a negative shift in the reference point is introduced. This situation is related to the increased feeling of responsibility under negative circumstances (Zeelenberg and Pieters, 2007). In this context, the effect of negative shift in reference point on logistics managers' approach to choice should be further investigated. Another interesting finding was the differences observed between the two versions of proposed MXL models. The specified models assuming a constrained triangular distribution suggested a statistically significant improvement in RRM only in the shock scenario, where RRM exhibited better ability than RUM in terms of measuring the correlation among similar alternatives.

Adopting the idea that the use of the two choice paradigms better represents choices by incorporating differences in the choice behavior of different respondents 
(Boeri et al., 2012), we further investigated RR-MNL and RU-MNL by examining elasticities and forecasting choice probability. We found that choices in freight transport can be influenced by regret and that managers who minimize anticipated regret can differ from managers who maximize expected utility. In line with previous studies, such as Hensher et al. (2011) and Thiene et al. (2012), we found that the two models generate different elasticity values and different probability forecasting, implying different policy appraisals. For example, RR and RU generated similar elasticities in the baseline scenario; however, RR generated higher elasticities than RU for more parameters and alternatives in the shock scenario. Furthermore, in the policy scenario where increased congestion was simulated for the status quo alternative in the two experiments, we found that the RR-MNL model exhibited the same market share decrease in the two experiments. In contrast, the RU-MNL model exhibited a slightly larger decrease in the first experiment compared with the second experiment.

Our research provides different avenues for future research. The investigation of reference-dependent specifications within the RRM approach is an interesting area for future research. This study is the first to analyze the RRM and RUM choice paradigms in freight transport. Future studies should explore the use of both models in related contexts such as in the regulation of freight transport. Finally, although our research examined taste heterogeneity within each choice paradigm, future studies should examine how observed socio-economic characteristics and interactions with generic variables can describe heterogeneity within both RU and RR. 


\section{References}

Bell, D.E., 1982. Regret in decision making under uncertainty. Operations Research, 30(5), 961-981.

Ben-Akiva, M. and Lerman, S.R., 1985. Discrete choice analysis: theory and application to travel demand. The MIT Press, Cambridge, Mass.

Ben-Akiva, M.E. and Swait, J., 1986. The Akaike likelihood ratio index. Transportation Science, 20(2), 133-136.

Bierlaire M., 2003. BIOGEME: a free package for the estimation of discrete choice models.

Bierlaire M., 2009. An introductory tutorial to BIOGEME Version 1.8. Monte Verita, Ascona, Switzerland.

Boeri, M.,2011. Advances in Stated Preference Methods: Discrete and continuous Mixing distributions in Logit models for representing variance and taste heterogeneity, $\mathrm{PhD}$ thesis, Queen's University of Belfast, School of Biological Sciences - Gibson Institute for Land, Food and the Environment.

Boeri, M., Longo, A., Doherty, E. and Hynes, S., 2012. Site choices in recreational demand: a matter of utility maximization or regret minimization? Journal of Environmental Economics and Policy, 1(1), 32-47.

Boeri, M., Longo, A., Grisola, J., Hutchinson, W. and Kee, F.,2013. The role of regret minimization in lifestyle choices affecting the risk of coronary heart disease, Journal of Health Economics 32(1): 253-260.

Connolly, T. and Reb, J., 2005. Regret in cancer-related decisions. Health Psychology, 24(4), 29-34.

Chorus, C.G., 2012a. Regret theory-based route choices and traffic equilibria, Transportmetrica, 8(4), 291-305.

Chorus, C.G, 2012b. Random Regret-based discrete choice modeling: A tutorial. Springer, Heidelberg, Germany.

Chorus, C.G., 2012c. Random Regret Minimization: An Overview of Model Properties and Empirical Evidence, Transport Reviews, 32(1), 75-92.

Chorus, C.G., 2010. A new model of Random Regret Minimization. European Journal of Transport and Infrastructure Research, 10(2), 181-196. 
Chorus, C.G., Annema, J., Mouter, N. and van Wee, G.P., 2011. Modelling politicians' preferences for road pricing policies: a regret-based and utilitarian perspective. Transport Policy, 18(6), 856-861.

Chorus, C.G., Arentze, T.A., and Timmermans, H.J.P., 2008. A Random Regret Minimization model of travel choice. Transportation Research Part B, 42(1), 18.

Chorus, C.G., Arentze, T.A. and Timmermans, H.J.P., 2009. Spatial choice: A matter of utility or regret? Environment and Planning Part B,36(3), 538-551.

Chorus, C.G. and de Jong, G.C., 2011. Modelling experienced accessibility for utility maximizers and regret-minimizers. Journal of Transport Geography, 19, 11551162.

Chorus, C.G., Molin, E.J.E., van Wee, G.P., Arentze, T.A. and Timmermans, H.J.P., 2006. Responses to transit information among car-drivers: Regret-based models and simulations. Transportation Planning and Technology, 29(4), 249-271.

Chorus, C.G. and Rose, J.M., 2011. Selecting a date: A matter of regret and compromises. Paper presented at the 2nd International Choice Modelling Conference, Leeds, UK.

Daly, A., Hess, S. and Train, K. E., 2009. Assuring finite moments for willingness to pay in random coefficient models, European Transport Conference, Noordwijkerhout.

Hess, S., Stathopoulos, A. and Daly, A., 2012. Allowing for heterogeneous decision rules in discrete choice models: an approach and four case studies. Transportation, 39(3), 565-591

Hess, S., Train, K. and Polak, J., 2006. On the use of a modified Latin hypercube sampling (MLHS) method in the estimation of a mixed logit model for vehicle choice. Transportation Research Part B: Methodological 40(2), 147-167.

Hensher, D. A., Greene, W. H. and Chorus, C. G., 2011. Random regret minimization or random utility maximization: an exploratory analysis in the context of automobile fuel choice. J. Adv. Transp.. doi: 10.1002/atr.188

Hensher, D. A. and Greene,W. H., 2003. The mixed logit model: the state of practice. Transportation, 30, 133-176. 
Hynes, S., Hanley, N. and Scarpa, R., 2008. Effects on welfare measures of alternative means of accounting for preference heterogeneity in recreational demand models, American Journal of Agricultural Economics, 90, 1011-1027.

Kaplan S. and Prato C.G., 2012. The application of the random regret minimization model to drivers' choice of crash avoidance maneuvers. Transportation Research Part F: Traffic Psychology and Behaviour, 15(6), ISSN 1369-8478, 10.1016/j.trf.2012.06.005.

Lawrence, C., Zhou, J. and Tits, A., 1997. User's Guide for CFSQP Version 2.5: A C Code for Solving (Large Scale) Constrained Nonlinear (Minimax) Optimization Problems, Generating Iterates Satisfying All Inequality Constraints. Institute for Systems Research, University of Maryland.

Loomes, G. and Sugden, R., 1982. Regret-Theory: An alternative theory of rational choice under uncertainty. The Economic Journal, 92(368), 805-824.

Masiero, L. and Maggi, R., 2012. Estimation of indirect cost and evaluation of protective measures for infrastructure vulnerability: A case study on the transalpine transport corridor. Transport Policy, 20, 13-21.

Masiero, L. and Henhser, D.A., 2011. Shift of reference point and implications on behavioral reaction to gains and losses. Transportation, 38, 249-271.

McFadden, D. and Train, K., 2000. Mixed MNL Models for Discrete Response. Journal of Applied Econometrics, 15(5), 447-470.

McFadden, D., 1974. Conditional logit analysis of qualitative choice-behaviour. In Zarembka, P., (Ed.) Frontiers in econometrics, Academic Press, New York.

Manski, C.F., 1977. The structure of random utility models. Theory and Decision, 8(3), 229-254.

Pathan, A.F.H., 2010. Modelling travellers' choices of information sources and of mode. Thesis (PhD). The University of Leeds.

Rigby, D. Balcombe, K. and Burton, M., 2009. Mixed logit model performance and distributional assumptions: preferences and GM foods. Environmental and Resource Economics, 42, 279-295.

Sarver, T., 2008. Anticipating regret: Why fewer options may be better. Econometrica, 76(2), 263-305. 
Savage, L.J., 1954. The Foundations of Statistics. New York: Wiley.

Scarpa, R., Thiene, M. and Marangon, F., 2008. Using flexible taste distributions to value collective reputation for environmentally friendly production methods. Canadian journal of agricultural economics-revue canadienne d'agroeconomie, 56(2), 145-162.

Sillano, M. and Ortúzar, J. D., 2005. Willingness-to-pay estimation with mixed logit models: some new evidence. Environment and Planning A, 37, 525-550.

Simonson, I., 1992. The influence of anticipating regret and responsibility on purchasing decisions. Journal of Consumer Research, 19(1), 105-119.

Thiene, M., Boeri, M. and Chorus, C.G., 2012. Random Regret Minimization: Exploration of a New Choice Model for Environmental and Resource Economics. Environmental and Resource Economics, 51(3), 413-429.

Thurstone, L.L., 1927. A law of comparative judgment. Psychological Review, 34, 273286.

Train, K. E., 2009. Discrete choice methods with simulation, 2nd edition. Cambridge University Press, Cambridge (MA, USA).

Walker, J. L., Ben-Akiva, M. and Bolduc, D. (2007), Identification of parameters in normal error component logit-mixture (NECLM) models. J. Appl. Econ., 22: 1095-1125.Zeelenberg, M. and Pieters, R., 2007. A theory of regret regulation 1.0. Journal of Consumer Psychology, 17(1), 3-18.

Zeelenberg, M., 1999. The use of crying over spilled milk: A note on the rationality and functionality of regret. Philosophical Psychology, 12(3), 325-340. 
Table 1. Description of the stated preference experiments 
Table 2. RU-MNL and RR-MNL in the first and second experiments (405 observations)

\begin{tabular}{|c|c|c|c|c|c|c|c|c|}
\hline & \multicolumn{4}{|c|}{ First experiment (base scenario) } & \multicolumn{4}{|c|}{ Second experiment (shock scenario) } \\
\hline & \multicolumn{2}{|c|}{ RU-MNL } & \multicolumn{2}{|c|}{ RR-MNL } & \multicolumn{2}{|c|}{ RU-MNL } & \multicolumn{2}{|c|}{ RR-MNL } \\
\hline & Value & $\mid$ t-stat $\mid$ & Value & $\mid$ t-stat| & Value & $\mid$ t-stat $\mid$ & Value & $\mid$ t-stat| \\
\hline Time & -0.069 & 2.74 & -0.046 & 2.82 & -0.113 & 5.44 & -0.060 & 6.08 \\
\hline Punt & 0.248 & 7.53 & 0.171 & 8.11 & 0.347 & 8.81 & 0.187 & 9.01 \\
\hline Cost & -0.005 & 6.09 & -0.004 & 6.01 & -0.005 & 8.75 & -0.004 & 9.24 \\
\hline ASC_PB & -0.964 & 6.7 & -0.608 & 7.46 & -0.32 & 2.12 & -0.158 & 2.35 \\
\hline ASC_TC & -0.757 & 5.53 & -0.482 & 6.19 & -0.384 & 2.55 & -0.19 & 2.83 \\
\hline ASC_SR & - & - & & - & -0.116 & 0.62 & -0.065 & 0.76 \\
\hline LL & & & & & & & & \\
\hline $\mathrm{rho}^{2}$ & & & & & & & & \\
\hline K & & & & & & & & \\
\hline
\end{tabular}

URL: http:/mc.manuscriptcentral.com/transportmetrica 
Table 3. RU-MXL and RR-MXL in the first and second experiments assuming normal distributions for random parameters (405 observations)

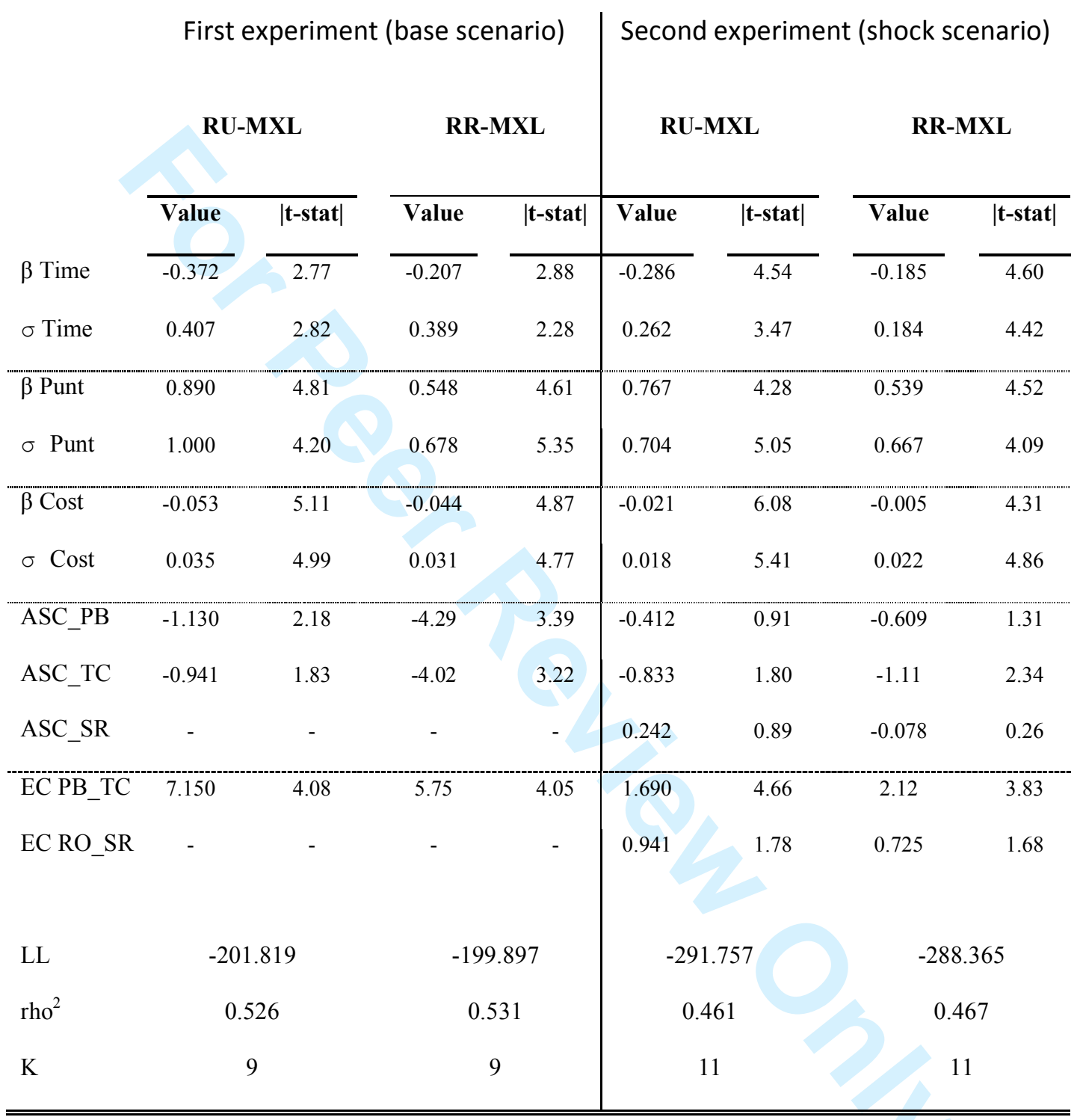


Table 4. RU-MXL and RR-MXL in the first and second experiments assuming constrained triangular distributions for random parameters (405 observations)

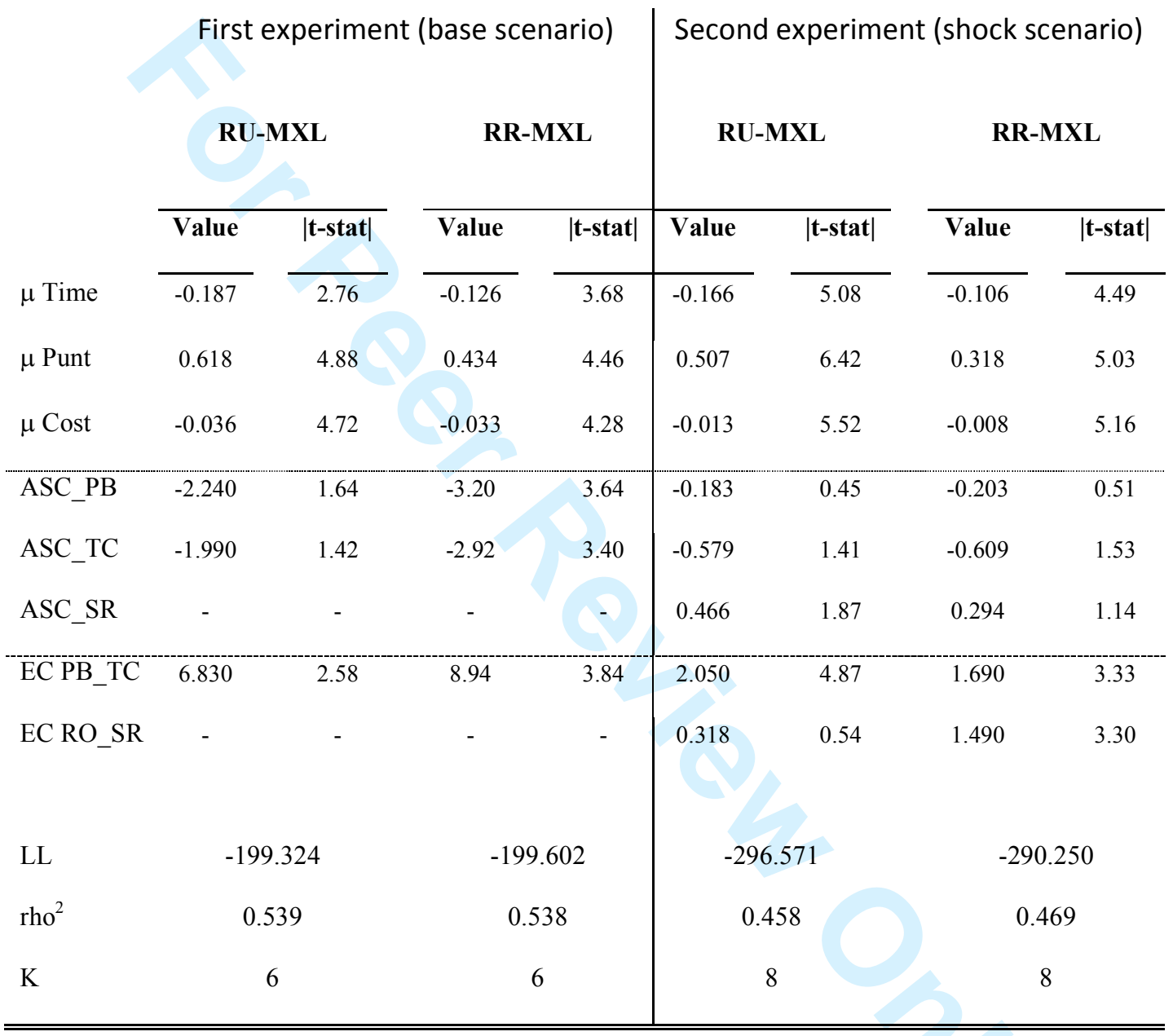

Note: $\mu$ is both the middle point and the spread of the triangular mixing distribution assumed for all three random taste coefficients. 
Table 5. Elasticities based on RU and RR in the first experiment

\begin{tabular}{|c|c|c|c|}
\hline \multicolumn{4}{|c|}{ Elasticities for the RU-MNL model } \\
\hline Change in & Piggyback & Combined transport & Road \\
\hline cost & -5.1 & -4.32 & -3.79 \\
\hline stdev & 5.01 & 4.4 & 4.21 \\
\hline time & -1.73 & -1.52 & -1.43 \\
\hline stdev & 1.45 & 1.34 & 1.4 \\
\hline punt & 18.38 & 16.29 & 13.54 \\
\hline stdev & 3.67 & 4.46 & 4.06 \\
\hline & & & \\
\hline \multicolumn{4}{|c|}{ Elasticities for the RR-MNL model } \\
\hline Change in & Piggyback & Combined transport & Road \\
\hline cost & -7.41 & -2.78 & -3.78 \\
\hline stdev & 7.2 & 2.71 & 3.82 \\
\hline time & -1.81 & -1.45 & -1.42 \\
\hline stdev & 1.48 & 1.23 & 1.29 \\
\hline punt & 15.21 & 18.06 & 16.22 \\
\hline stdev & 2.42 & 3.76 & 3.1 \\
\hline
\end{tabular}


Table 6. Elasticities based on RU and RR in the second experiment

\begin{tabular}{|c|c|c|c|c|}
\hline \multicolumn{5}{|c|}{ Elasticities for the RU-MNL model } \\
\hline Change in & Regulated road & Piggyback & Combined transport & Second best road \\
\hline cost & -6.47 & -6.6 & -6.71 & -7.83 \\
\hline stdev & 5.88 & 5.83 & 5.56 & 5.94 \\
\hline time & -3.12 & -3.23 & -3.29 & -3.83 \\
\hline stdev & 2.55 & 2.6 & 2.55 & 2.68 \\
\hline punt & 24.18 & 25.32 & 25.9 & 29.43 \\
\hline stdev & 7.73 & 7.56 & 6.9 & 2.27 \\
\hline \multicolumn{5}{|c|}{ Elasticities for the RR-MNL model } \\
\hline Change in & Regulated road & Piggyback & Combined transport & Second best road \\
\hline cost & -7.55 & -9.71 & -5.47 & $\begin{array}{l}-8.36 \\
\end{array}$ \\
\hline stdev & 6.23 & 7.88 & 4.18 & 6.27 \\
\hline time & -4.07 & -3.52 & -2.94 & -3.88 \\
\hline stdev & 3.01 & 2.6 & 2.13 & 2.68 \\
\hline punt & 34.22 & 20.84 & 28.17 & 30.11 \\
\hline stdev & 6.33 & 3.68 & 4.55 & 1.63 \\
\hline
\end{tabular}


Table 7. Predicted change in choice probabilities caused by a 15 percent increase in time for the preferred road (first experiment)

\begin{tabular}{|c|c|c|c|c|c|c|}
\hline \multicolumn{7}{|c|}{ RU-MNL } \\
\hline \multirow{2}{*}{ Choice } & \multicolumn{2}{|c|}{ Baseline } & \multicolumn{2}{|c|}{ Scenario } & \multicolumn{2}{|c|}{$\begin{array}{c}\text { Change } \\
\text { Scenario - Baseline }\end{array}$} \\
\hline & $\%$ share & Abs val. & $\%$ share & Abs val. & $\%$ share & Abs val. \\
\hline Piggyback & $24.20 \%$ & 98 & $27.00 \%$ & 109 & $2.80 \%$ & 11 \\
\hline Combined transport & $32.84 \%$ & 133 & $36.51 \%$ & 148 & $3.67 \%$ & 15 \\
\hline Road & $42.96 \%$ & 174 & $36.49 \%$ & 148 & $-6.47 \%$ & -26 \\
\hline \multicolumn{7}{|c|}{ RR-MNL } \\
\hline \multirow[t]{2}{*}{ Choice } & \multicolumn{2}{|c|}{ Baseline } & \multicolumn{2}{|c|}{ Scenario } & \multicolumn{2}{|c|}{$\begin{array}{c}\text { Change } \\
\text { Scenario - Baseline }\end{array}$} \\
\hline & $\%$ share & Abs val. & $\%$ share & Abs val. & $\%$ share & Abs val. \\
\hline Piggyback & $27.17 \%$ & 110 & $29.26 \%$ & 119 & $2.09 \%$ & 9 \\
\hline Combined transport & $33.56 \%$ & 136 & $36.11 \%$ & 146 & $2.55 \%$ & 10 \\
\hline Preferred road & $39.27 \%$ & 159 & $34.64 \%$ & 140 & $-4.64 \%$ & -19 \\
\hline
\end{tabular}


Table 8. Predicted change in choice probabilities caused by a15 percent increase in time for the second-best road (second experiment)

\begin{tabular}{|c|c|c|c|c|c|c|}
\hline \multicolumn{7}{|c|}{ RU-MNL } \\
\hline \multirow{2}{*}{ Choice } & \multicolumn{2}{|c|}{ Baseline } & \multicolumn{2}{|c|}{ Scenario } & \multicolumn{2}{|c|}{$\begin{array}{c}\text { change } \\
\text { Scenario - Baseline }\end{array}$} \\
\hline & $\%$ share & Abs val. & $\%$ share & Abs val. & $\%$ share & Abs val. \\
\hline Regulated road & $31.85 \%$ & 129 & $33.83 \%$ & 137 & $1.97 \%$ & 8 \\
\hline Piggyback & $27.90 \%$ & 113 & $29.60 \%$ & 120 & $1.70 \%$ & 7 \\
\hline Combined transport & $26.17 \%$ & 106 & $27.86 \%$ & 113 & $1.69 \%$ & 7 \\
\hline Second-best road & $14.07 \%$ & 57 & $8.72 \%$ & 35 & $-5.36 \%$ & -22 \\
\hline \multicolumn{7}{|c|}{ RR-MNL } \\
\hline \multirow[t]{2}{*}{ Choice } & \multicolumn{2}{|c|}{ Baseline } & \multicolumn{2}{|c|}{ Scenario } & \multicolumn{2}{|c|}{$\begin{array}{c}\text { Change } \\
\text { Scenario - Baseline }\end{array}$} \\
\hline & $\%$ share & Abs val. & $\%$ share & Abs val. & $\%$ share & Abs val. \\
\hline Regulated road & $28.62 \%$ & 115 & $30.21 \%$ & 121 & $1.59 \%$ & 6 \\
\hline Piggyback & $26.65 \%$ & 108 & $28.11 \%$ & 114 & $1.46 \%$ & 6 \\
\hline Combined transport & $25.83 \%$ & 105 & $27.27 \%$ & 110 & $1.44 \%$ & 5 \\
\hline Second-best road & $18.91 \%$ & 77 & $14.41 \%$ & 60 & $-4.49 \%$ & -17 \\
\hline
\end{tabular}

